\title{
A Longitudinal Study of Continued Tooth Eruption During Adulthood
}

\author{
Edward F. Harris* and Yoav Shiloah \\ College of Dentistry, University of Tennessee, Memphis, Tennessee
}

\begin{abstract}
Teeth retain their capacity to continue to erupt throughout life. What is less-well appreciated is that occlusal migration - with corresponding alveolar proliferation-continues as a normal process during adulthood. Historically, this continuous eruption has been viewed as accommodative for the loss of crown height due to serious occlusal abrasion. Nowadays, with only trivial wear, the result of continuous eruption is to increase lower face height during adulthood. This study reports on changes in the mandibular first and second molars in 73 Americans whites (63 females) examined at 17 and again at about 31 years of age. A computer-assisted method was used to measure alveolar and dental changes using the inferior alveolar canal as a fiducial benchmark. Each molar's image was scaled to the mesiodistal molar crown dimension
\end{abstract}

In spite of extensive work on the subject, the forces that cause a tooth to erupt-to move coronally into occlusion-are poorly understood (Marks and Cahill, 1984; Steedle and Proffit, 1985; Gorski and Marks, 1992; Wise et al., 2002). Indeed, research now suggests that much of the information gleaned from studying rodents (with rootless, continuously erupting incisors) may not apply to humans. Moreover, the forces responsible for a tooth's movement in its pre-emergent phase may be different from those that carry the erupted tooth into occlusion (Lee and Proffit, 1995; Trentini et al., 1995).

Tooth eruption conventionally refers to the rather rapid movement of a tooth from its formative position in its bony tooth crypt coronally into functional occlusion (Sato and Parsons, 1990). This is active tooth eruption and, for the permanent teeth, the eruptive phase (ignoring the third molars) starts around 6 years of age and is completed around 12 years of age (Hurme, 1949). Less well studied is the second, slow and protracted, albeit cumulative phase of tooth eruption termed continuous eruption. This consists of coronal movements of the permanent teeth that occur well after the active phase and that increases in crown height increase lower face height and change facial proportions with age (Iseri and Solow, 1996).

Early studies (Manson, 1963; Bhaskar, 1962) suggested that teeth moved coronally during adulthood such that the CEJ-to-crestal bone distance increases. The argument measured from that subject's dental cast. Major findings were: Both lower molars erupted during adulthood to statistically significant extents, more so in men. Alveolar bone proliferated apace with the coronal tooth migration, so the CEJ-to-crestal bone distance did not change in these healthy, young, dentate adults. First and second molar roots increased in length, apparently by the progressive deposition of cementum. Prior studies have documented continuous eruption in peoples with severe occlusal wear; this study shows that comparable increases occur without any macroscopic loss of tooth substance. These normative changes that-assumedly occur in both jaws-have discernible, cumulative effects on lower face height and facial proportions in adulthood. Dental Anthropology 2007;20:7-15.

was that teeth erupted more than bony remodeling could keep pace, thereby exposing more root coronal to the bone. These findings were readily criticized because inflammatory periodontitis - which has been prevalent (Carranza and Newman, 1996)-produces the same increase in CEJ-to-crestal bone distance over time.

Subsequent work shows that the "mobile" feature actually is both the tooth and the gingival and crestal bone (Murphy, 1959; Levers and Darling, 1983; Whittaker et al., 1990; Dannenberg et al., 1991). This difference in perspective was documented definitively by Iseri and Solow (1996) who studied cephalographs taken by Arne Björk of people in whom metallic implants had been placed (Björk, 1968). In contrast to conventional bony landmarks that remodel with age (e.g., Nasion, Menton), metallic implants remain immobile, sequestered in the bone proper (Enlow, 1977). These metallic implants serve as immobile fiducial landmarks against which skeletodental growth can be quantified without distortion (Björk and Skieller, 1972, 1977). Iseri and Solow studied subjects in their later teens and twenties, which is several years after the last teeth had erupted into occlusion (ignoring M3s). Findings were (A) that

${ }^{*}$ Correspondence to: Edward F. Harris, College

of Dentistry, University of Tennessee, Memphis,

Tennessee 38163

E-mail: eharris@utmem.edu 
continuous eruption was a normative consequence of ageing, (B) that that continuous eruption occurred in all teeth, and $(C)$ that there was greater coronal eruption of the distal teeth than the anterior teeth, so the occlusal plane flattened with age. While quite informative, this study was restricted to the study of females (one supposes that changes in males would be greater; Behrents, 1985; Bishara et al., 1994) and, again, most subjects were followed just to their early 20s. One considerable value of this study was its longitudinal design - the same individuals were examined serially - so individual changes with time could be quantified.

Cross-sectional data are, however, far more available. A key study in this area was by Varrela and coworkers (1995). Varrela examined archeologically derived material from a European archeological site and grouped the mandibles into age intervals based on age at death. Results showed that even accounting for the insensitive cross-sectional nature of the design, continuous eruption-measured as increasing distance from the cementoenamel junction (CEJ) to the inferior alveolar canal - was evident.

As in the study by Varrela, most peoples (historically and prehistorically) have exhibited appreciable occlusal wear, which reduces crown height. It commonly has been speculated that continuous eruption is an adaptive, accommodative response to the need to extend a tooth's functional longevity. Continuous eruption provides greater tooth mass before, as was common, occlusal attrition wears the tooth to the gum line. Begg, speaking of the prehistoric Australian condition, contended that, "Tooth eruption does not stop at the neck of the teeth, but proceeds apically to the ultimate shedding of the teeth if we live long enough. Continued tooth eruption rendered continual tooth attrition harmless" (Begg and Kesling, 1971:26). Nowadays, with virtually no grit in the diet, occlusal attrition is trivial, even in advanced age, so this accommodative increase in crown height provides no selective advantage. Instead, continuous eruption without occlusal attrition simply increases lower face height.

Purpose of the present study was to test whether continuous eruption is discernible in a sample of contemporary Americans who were followed radiographically from their mid-teens to about 30 years of age. The sample consists of people who had received comprehensive orthodontic treatment starting at the conventional age of around 13 years of age, with completion around 16 years of age. The cases were reexamined at a long-term follow-up at an average of 30.7 years of age. This study reports on continuous eruption of the mandibular molars between these two examinations (ca. 17 and 31 years of age).

\section{MATERIALS AND METHODS}

Data for this study were collected from an on-going project involving the long-term recall of patients who, at adolescence, had received comprehensive orthodontic treatment. The end of treatment averaged 16.7 years (sd $=1.8$ years), and the average age at the recall examination was 30.7 years ( $\mathrm{sd}=6.8$ years), so the mean duration was 14.0 years. Statistically, there was no difference in any age parameter between males and females. All of the subjects in this study $(\mathrm{n}=73)$ are American whites, and there is a preponderance of females $(n=63)$ because several women had their recall examination when they brought their own child to the orthodontist for treatment.

A computer-assisted photogrammetric method was used to obtain the measurements. The panoramic film was digitized at high resolution on a flat-bed scanner, and the image was imported into SigmaScan Pro 5.0 (SPSS Inc., Chicago, IL), where the image was enlarged several-fold (which facilitates landmark location but does not affect actual dimensions), landmarks were located, and the program generated the desired variables.

Reliance on panoramic radiographs introduces variability because the source-to-film distance and the object-to-film distance are only approximately standardized. When taking a given film, the operator chooses from among a few pre-set trough paths based on the patient's size and facial form. The "trough" is the two-dimensional pathway that the source (cathode) tracks around the person's head. Ideally, the trough scribed by the machine parallels the shape of the person's dental arches.

Landmark studies regarding continuous eruption (Thompson and Kendrick, 1964; Levers and Darling 1983) used data collected from panoramic radiographs, though their data were cross-sectional. When studying skeletal specimens, radiation exposure is irrelevant, and bone-holding devices can be rigged to provide stationary periapical (or equivalent) X-rays with known radiographic magnification (Whittaker et al., 1990). In the future, the increasingly prevalent use of three-dimensional cone-beam computed tomography will provide measurements that are fully corrected for magnification (e.g., Cevidanes et al., 2006, 2007). Such long-term longitudinal data are not, however, available now, so we felt warranted in using the panoramic data to test-using longitudinal data-whether changes in tooth length are discernible. In our opinion, long-term longitudinal radiographic data on the living are scarce enough that analysis is warranted-given appropriate caveats-even though the X-rays cannot be exactly standardized.

Measurements were made using a common technique (Whittaker et al., 1985; Varrela et al., 1995). The inferior alveolar canal was used as the fiducial landmark. The invariance of this neural structure has been confirmed by the metallic implant studies of Björk $(1956,1963)$. The longitudinal midline of a molar was defined by visual best fit (Fig. 1). Four landmarks were located along this line: (1) the cementoenamel junction (CEJ); (2) height of 
the crestal bone along the molar's midline; (3) the apical plane defined by the line through the tooth's mesial and distal root apices; and (4) superior aspect of the cortical bones of the inferior alveolar canal. In addition, we measured the height of the crestal bone separately at the mesial and distal aspect of the molar down to the IAC measured parallel with the molar's long axis.

There is no absolute scale on a panoramic radiograph, so we scaled each image to millimeters by using the specific molar's mesiodistal crown diameter measured from the dental cast taken at the same appointment. Tooth dimensions were obtained in a standardized manner (Moorrees, 1957) using sliding calipers. In other words, each individual molar's mesiodistal crown size was recorded from its panoramic image and from the associated dental cast, and the computer measurements were scaled to millimeters for each tooth. A panoramic radiographic image exhibits variable magnification because the X-ray head is not everywhere equidistant from the dental structures (Graber, 1967), but the pathway is least curvilinear in the buccal segment where the molars are situated. As described below, the complex of skeletodental changes found here cannot be explained by differences in magnification.

The inferior alveolar canal in the mandible is visible radiographically starting at the lingula and descending downward-and-forward to the premolar region where, in our experience, it seldom can be followed any farther. Consequently, we only measured the first and second molars. So far as possible, all four molars in the lower two quadrants were measured, but teeth with poor images were omitted. These young adults were in reasonably good oral health, and each molar was in contact with the tooth mesial to it, so there was no apparent instance of tipping. Also, all molars had an antagonist.

Measurement error is an issue because the changes are fairly subtle. Repeatability error was assessed using the conventional Dahlberg statistic (Dahlberg, 1940; Bland and Altman, 1996) and the intraclass correlation coefficient (from nested analysis of variance), which is the proportion of the total variation due to differences between measurements of the same individuals (i.e., repeatability error). There was no substantive difference among the types of variables, and, overall, Dahlberg's d was $0.31 \mathrm{~mm}$. That is, the average error due to discrepancies in measurement was one-third of a millimeter, which is appreciably less than any of the statistically significant differences found here. The intraclass correlation was 0.987 , meaning that just $1.3 \%$ of the observed variation was attributable to discrepancies in measuring the same dimensions repeatedly.

Statistically, repeated-measures analysis of variance was used to exploit the longitudinal nature of the data as well as the paired M1-M2 comparisons within individuals (Winer et al., 1991; Sokal and Rohlf, 1995). Statistics were calculated using JMP 5.0.2 (SAS Institute Inc., Cary, NC).

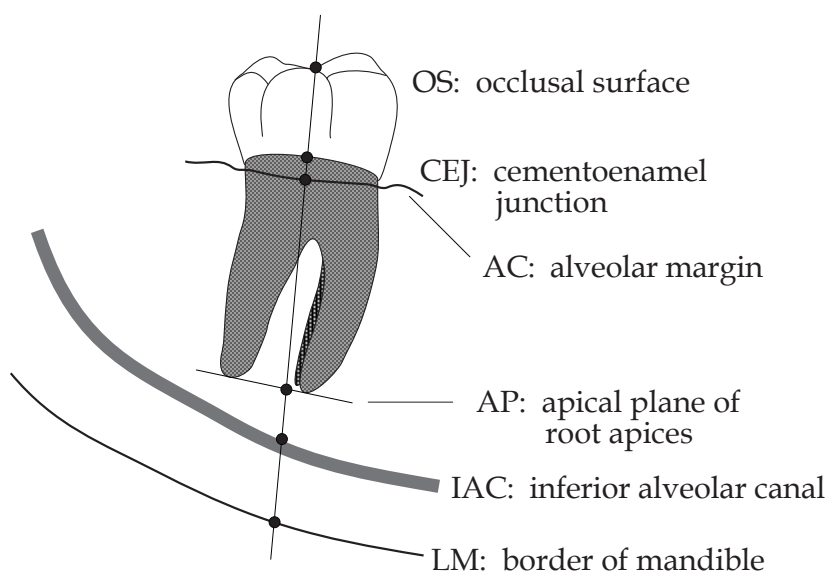

Fig. 1. Diagram showing the landmarks that were digitized for each mandibular molar. The vertical line through the tooth defines its long axis, and measurements were made along this best-fit line. The landmarks, from top to bottom, depict the crown's occlusal surface (OS), the CEJ, the alveolar crest (at its intersection with the tooth's long axis), the root apex (where a line defined by the mesial and distal roots crosses the long axis), the inferior alveolar canal, and the inferior border of the mandibular corpus.

\section{RESULTS}

Descriptive statistics are presented separately by sex because, as is characteristic (Behrents, 1985; Bishara et al., 1994), males exhibit more facial growth during their teens and early twenties. Also, changes in the first and second molar are described separately because, while the changes are comparable, the second molar is smaller, closer to the inferior alveolar canal (IAC), and migrates occlusally somewhat less than M1 (Table 1).

\section{First Molar}

At $\mathrm{T} 1$ (mean $=16.7$ years) the root apices were about $5 \mathrm{~mm}$ above the IAC, and, as shown in Table 2, this distance increased to about $6 \mathrm{~mm}$ at T2 (mean $=30.7$ years). This increase-adjusted to one decade of change across all subjects (Table 3 ) - was about $1 \mathrm{~mm}$ / decade in males and half this (which is significantly less) in females, with both changes being highly significant statistically. If, instead, one measures the distance from the IAC up to the CEJ, these increases are appreciably larger. The change in the IAC-CEJ distance was $1.7 \mathrm{~mm} /$ decade in males and $1.0 \mathrm{~mm} /$ decade in females. Again, both of these increases are highly significant (Table 3), and the change in men significantly exceeds that in women (Table 4).

The difference between these two distances (IAC to $\mathrm{AP}$ and IAC to CEJ) is informative in that it shows that, while M1 is erupting occlusally, there is evidence 
TABLE 1. Results of two-way analysis of variance testing for size differences between molars and by sex ${ }^{1}$

\begin{tabular}{lrrrrrr}
\hline \multicolumn{1}{c}{ Variable } & \multicolumn{2}{c}{ Molar $^{2}$} & \multicolumn{2}{c}{ Sex } & \multicolumn{2}{c}{ Molar-x-Sex } \\
& F Ratio & P value & F Ratio & P value & F Ratio & P value \\
\hline IAC to AP, T1 & 34.43 & $<0.0001$ & 0.13 & 0.7169 & 1.97 & 0.2807 \\
IAC to AP, T2 & 54.28 & $<0.0001$ & 0.00 & 0.9837 & 0.10 & 0.7538 \\
IAC to CEJ, T1 & 245.71 & $<0.0001$ & 0.00 & 0.9411 & 0.02 & 0.8920 \\
IAC to CEJ, T2 & 310.50 & $<0.0001$ & 1.62 & 0.2111 & 2.78 & 0.1037 \\
Root Length, T1 & 70.69 & $<0.0001$ & 0.46 & 0.4997 & 2.06 & 0.1592 \\
Root Length, T2 & 67.41 & $<0.0001$ & 5.30 & 0.0267 & 3.35 & 0.0749 \\
CEJ to Crestal Bone, T1 & 3.55 & 0.0747 & 0.53 & 0.4698 & 1.16 & 0.2886 \\
CEJ to Crestal Bone, T2 & 0.55 & 0.4643 & 3.02 & 0.0901 & 0.11 & 0.7379 \\
IAC to Crestal Bone, Mesial T1 & 93.47 & $<0.0001$ & 0.02 & 0.9007 & 0.03 & 0.8686 \\
IAC to Crestal Bone, Mesial T2 & 153.86 & $<0.0001$ & 0.98 & 0.3275 & 3.43 & 0.0716 \\
IAC to Crestal Bone, Distal T1 & 169.55 & $<0.0001$ & 0.00 & 0.9910 & 0.69 & 0.4115 \\
IAC to Crestal Bone, Distal T2 & 253.98 & $<0.0001$ & 0.18 & 0.6736 & 1.15 & 0.2891 \\
\hline
\end{tabular}

${ }^{1}$ Numerator $\mathrm{df}$ is 1 and denominator $\mathrm{df}$ is 40 for each test.

2Both M1 and M2 could be measured for most subjects, so "Molar" was treated as a repeated measure, which provides greater statistical power (but limits the sample sizes to cases where both molars were measurable). The ANOVA is, then, a mixed model.

TABLE 2. Descriptive statistics, by sex

\begin{tabular}{lcrrrrr}
\hline \multicolumn{1}{c}{ Variable } & \multicolumn{3}{c}{ Males } & \multicolumn{3}{c}{ Females } \\
& $\mathrm{n}$ & Mean & $\mathrm{sd}$ & $\mathrm{n}$ & $\mathrm{Mean}$ & $\mathrm{sd}$ \\
\hline & \multicolumn{3}{c}{ Mandibular First Molar } & & & \\
IAC to AP, T1 & 15 & 5.00 & 2.18 & 84 & 5.49 & 2.01 \\
IAC to AP, T2 & 15 & 6.24 & 2.45 & 84 & 6.03 & 2.02 \\
IAC to CEJ, T1 & 15 & 18.89 & 1.96 & 84 & 19.06 & 2.59 \\
IAC to CEJ, T2 & 15 & 21.08 & 3.00 & 84 & 20.15 & 2.61 \\
Root Length, T1 & 15 & 13.88 & 1.16 & 84 & 13.57 & 1.66 \\
Root Length, T2 & 15 & 14.84 & 2.03 & 84 & 14.11 & 1.57 \\
CEJ to Crestal Bone, T1 & 15 & 1.82 & 0.35 & 84 & 1.98 & 0.55 \\
CEJ to Crestal Bone, T2 & 15 & 2.11 & 0.56 & 84 & 1.98 & 0.57 \\
IAC to Crestal Bone, Mesial T1 & 15 & 17.94 & 2.13 & 84 & 18.27 & 2.09 \\
IAC to Crestal Bone, Mesial T2 & 15 & 19.77 & 2.83 & 84 & 19.07 & 2.12 \\
IAC to Crestal Bone, Distal T1 & 15 & 15.81 & 2.51 & 84 & 16.45 & 2.20 \\
IAC to Crestal Bone, Distal T2 & 15 & 17.58 & 2.99 & 84 & 17.48 & 2.17 \\
& Mandibular Second Molar & & & \\
IAC to AP, T1 & 10 & 4.48 & 2.02 & 50 & 4.30 & 2.56 \\
IAC to AP, T2 & 10 & 5.16 & 2.30 & 50 & 4.88 & 2.65 \\
IAC to CEJ, T1 & 10 & 16.72 & 2.27 & 50 & 16.40 & 2.63 \\
IAC to CEJ, T2 & 10 & 18.75 & 3.39 & 50 & 17.36 & 2.88 \\
Root Length, T1 & 10 & 12.24 & 0.95 & 50 & 12.09 & 1.76 \\
Root Length, T2 & 10 & 13.58 & 2.07 & 50 & 12.48 & 1.77 \\
CEJ to Crestal Bone, T1 & 10 & 1.83 & 0.37 & 50 & 1.85 & 0.50 \\
CEJ to Crestal Bone, T2 & 10 & 2.32 & 0.42 & 50 & 2.03 & 0.59 \\
IAC to Crestal Bone, Mesial T1 & 10 & 16.38 & 2.78 & 50 & 16.18 & 2.35 \\
IAC to Crestal Bone, Mesial T2 & 10 & 17.58 & 3.33 & 50 & 16.91 & 2.52 \\
IAC to Crestal Bone, Distal T1 & 10 & 13.70 & 2.84 & 50 & 13.50 & 2.17 \\
IAC to Crestal Bone, Distal T2 & 10 & 14.57 & 3.24 & 50 & 14.41 & 2.46 \\
\hline
\end{tabular}




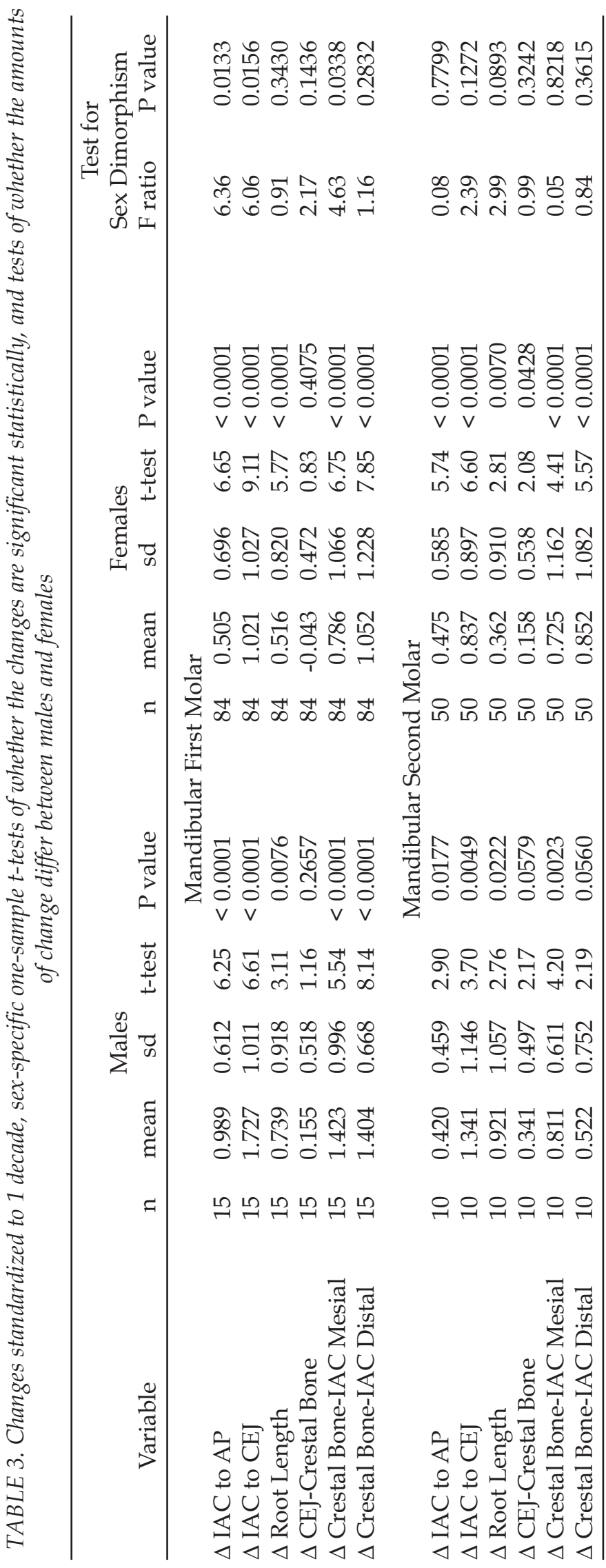

of root remodeling (probably cementum deposition) that lengthens the roots and diminishes the apparent movement of the teeth away from the IAC. In other words, the roots lengthened from $\mathrm{T} 1$ to $\mathrm{T} 2$, and the increase was about $0.6 \mathrm{~mm} /$ decade in both sexes (Fig. 2).

The other measurements (Tables 1-2) define the molar's relationship to the crestal bone. The vertical distance from the CEJ to the crestal bone (measured at the middle of the crown; Fig. 1) did not change with time in these healthy subjects. The distance is just under 2 $\mathrm{mm}$ at both examinations. On the other hand, measuring height of the CEJ vis-à-vis the IAC makes it evident that the alveolar bone is appositional with age, such that its height increases an average of $1.4 \mathrm{~mm} /$ decade in men and a bit less in women (Table 3). So, while M1 is slowly erupting to the occlusal, alveolar bone being is deposited to keep pace. Table 2 shows that the crestal bone height is roughly $2 \mathrm{~mm}$ greater on the mesial than the distal aspect of M1, but this merely reflects the upward curvature of the IAC as it courses distally toward the lingula.

\section{Second Molars}

As shown by the ANOVA tests in Table 1, almost all of the dimensions taken at the second molar are substantially different than for M1. This primarily has to do with the upward curve of the IAC as it passes beneath this distal molar that provide different distances to the bone and tooth structures compared to M1. While the dimensions differ between teeth, the changes for M1 and $\mathrm{M} 2$ are comparable. At T1, apices of the M2 roots were about $4.5 \mathrm{~mm}$ superior to the IAC, and this distance increased to about $5.0 \mathrm{~mm}$ at T2. Adjusted to change-perdecade, the IAC-AP distances increased about one-half millimeter per decade in both sexes. Again, this distance was attenuated by remodeling of the root apices because the increase in the distance from the IAC up to the CEJ is twice as great (Table 3), averaging $1.3 \mathrm{~mm} /$ decade in men and $0.8 \mathrm{~mm} /$ decade in women.

At T2, there is suggestive evidence of some crestal bone loss with age, averaging 0.2 to $0.3 \mathrm{~mm} /$ decade, which is only marginally significant statistically $(\mathrm{P}=0.06$ in men; $\mathrm{P}=0.04$ in women). Of note, the net remodeling of bone around $\mathrm{M}$ is appositional, because there are increases of around $0.8 \mathrm{~mm} /$ decade when bone height is measured relative to the invariant IAC rather than the upwardly-migrating tooth.

\section{DISCUSSION}

\section{Alveolar Bone}

Enlow and Harris (1964) showed that the corpus is everywhere appositional throughout the active phase of growth, so width and height (and mechanical resilience) of the corpus increase with age. Israel (1979) documented that these trends continue well into adulthood. In the present study, dealing with dentate 
TABLE 4. Results of two-way analysis of variance testing for differences in changes (standardized to 1 decade) from T1 to T2 between molars and by sex ${ }^{1}$

\begin{tabular}{lrrrrrr}
\hline \multirow{2}{*}{ Variable } & \multicolumn{2}{c}{ Molar } & \multicolumn{2}{c}{ Sex } & \multicolumn{2}{c}{ Molar-x-Sex } \\
F Ratio & P value & F Ratio & P value & F Ratio & P value \\
\hline IAC to AP & 1.27 & 0.2669 & 0.06 & 0.8123 & 0.32 & 0.5766 \\
IAC to CEJ & 1.83 & 0.1834 & 3.89 & 0.0457 & 1.38 & 0.2470 \\
Root Length & 0.01 & 0.9202 & 5.49 & 0.0243 & 0.28 & 0.6006 \\
CEJ-Crestal Bone & 0.97 & 0.3298 & 5.63 & 0.0226 & 1.35 & 0.2514 \\
IAC to Crestal Bone, Mesial & 3.66 & 0.0631 & 0.67 & 0.4187 & 2.66 & 0.1111 \\
IAC to Crestal Bone, Distal & 6.38 & 0.0157 & 0.03 & 0.8715 & 2.33 & 0.1349 \\
\hline
\end{tabular}

${ }^{1}$ These are mixed-model ANOVA tests, with repeated measures on Molar while Sex is a fixed effect; degrees of freedom are 1 and 39 for each test.

young adults, alveolar bone continued to be deposited along the surface such that corpus height provided by the alveolar crestal bone (above the IAC) increased about $1.5 \mathrm{~mm} /$ decade in men and just under $1 \mathrm{~mm} /$ decade in women. This bony apposition increases lower face height. The rate is significantly slower in women, though still significant statistically.

Continuous tooth eruption keeps pace with the proliferation of alveolar bone. Indeed, in these healthy young adults, the distance from the CEJ down to the crestal bone did not change with age even though the molars moved coronally about $1 \mathrm{~mm}$ in women and an average of $2 \mathrm{~mm}$ in men (Table 2).

The question of whether the CEJ has a constant relationship with crestal bone (CB) with advancing age has been contentious, primarily because an increase in this distance can more parsimoniously be attributed to chronic inflammatory periodontal disease than to continued tooth eruption. Danenberg et al. (1991) documented significant increases in the CEJ-CB distance with advancing age in Australian Aborigines. These authors found no bony evidence of periodontal disease and contended that the increases were evidence of continued tooth eruption during adulthood. Other

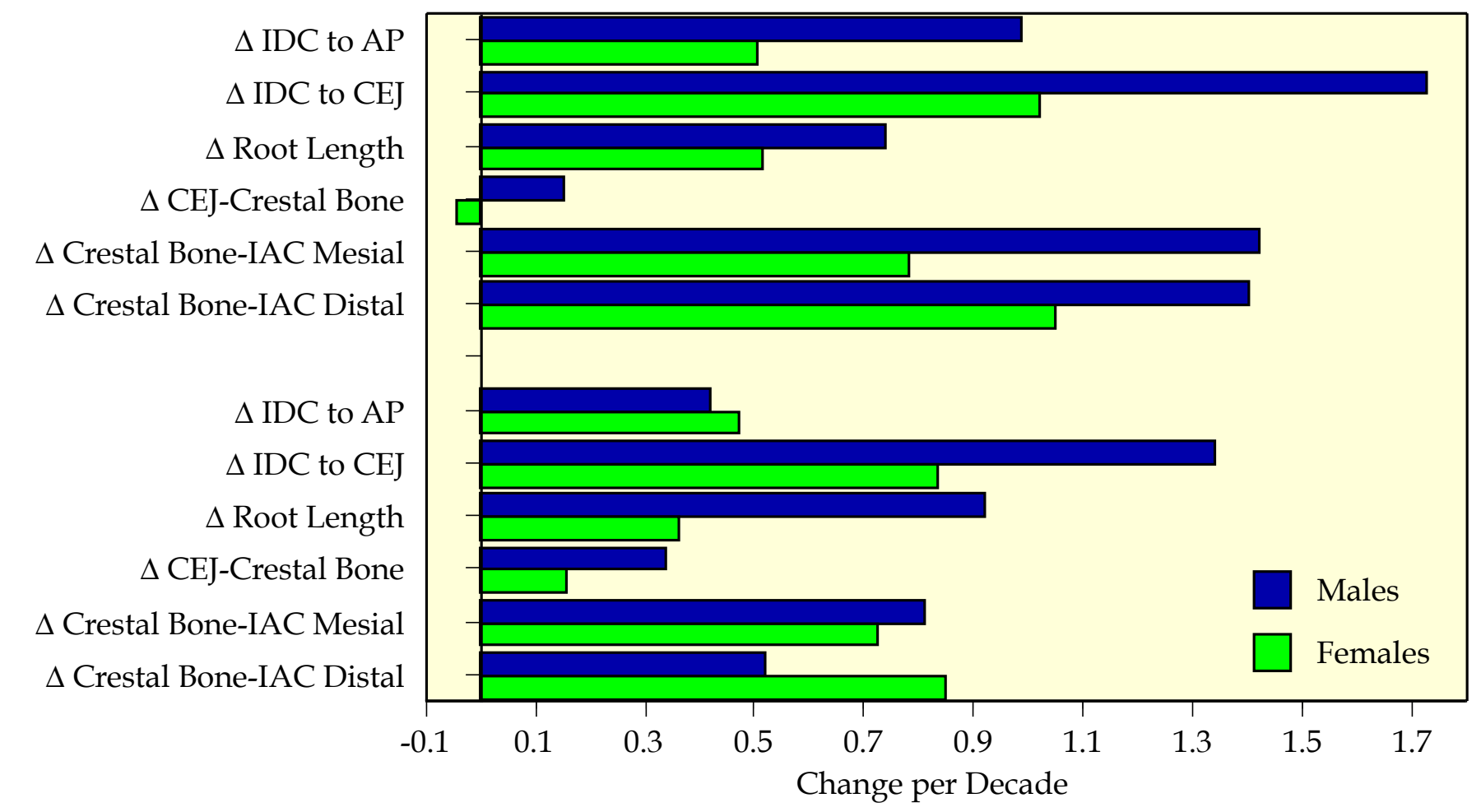

Fig. 2. Dimensional changes in lower molars, by sex and molar. The T1 to T2 changes have been standardized to one decade (10 years) on an individual basis. 
researchers (Whittaker et al., 1990; Varrela et al., 1995) found only small, statistically nonsignificant increases in the CEJ-CB distance with advancing age. There was no change in this distance in the present study, though these adults may be too young and the interval may be too short to disclose such changes. During the observed age interval, the molars erupted significantly, especially in men, but alveolar bony proliferation was fully as aggressive.

\section{Continuous Eruption}

Continuous eruption refers to a tooth's life-long potential to further erupt. This capacity is readily observed in people who have lost an antagonist, where the unimpeded tooth supererupts (e.g., Compagnon and Woda, 1991; Yonezu and Machida, 1997). Similarly, orthodontists have experience "helping" a tooth erupt with the use of traction forces (e.g., Stevens and Levine, 1998; Durham et al. 2004) virtually regardless of the patient's age. The antithesis of this phenomenon is the ankylosed tooth (and osseointegrated implant) that becomes progressively submerged as adjacent teeth and surrounding alveolar bone continue to migrate occlusally (Ödman et al., 1991; Roberts, 1994). Of more general relevance, is whether continuously eruption is a dentition-wide phenomenon that characteristically occurs in all adults? Prior studies (Newman and Levers, 1979; Whittaker et al., 1982, 1985, 1990; Varrela et al., 1995) have shown that continous eruption does occur during adulthood, but (A) these studies have been crosssectional, based on skeletal remains of subjects who died at different ages, (B) most studies have combined males and females, and (C) studies have used peoples who experienced moderate-to-severe occlusal wear because they lived on coarse, abrasive diets. It might be argued (Levers and Darling, 1983) that substantial occlusal wear increases freeway space, thereby "making room" for additional, compensatory tooth eruption. What happens in the absence of attrition? The modern American diet is so highly refined and grit-free that young adults present without any wear facets and most people never experience dentin exposure due to dietary abrasion. Consequently, there is only inconsequential loss of vertical dental height.

The theme of some studies has been that continous eruption occurs because of substantial attrition. For example, Begg (1954) contended that the severe occlusal wear that occurred in prehistoric Australian Aboriginals "made room" for the teeth to erupt farther. Murphy (1959), Levers and Darling (1983), and several others likewise have assumed that continuous eruption is the respondent and occurred when the opportunity was created by occlusal abrasion. As seen in the present study, eruption is occurring continuously and seemingly at equivalent rates even in the absence of any macroscopic abrasion. Whittaker et al. (1990) reported comparable findings from a 19th century British series where abrasion was slight. It seems that eruption is an ongoing physiological process that is indifferent to whether the crowns are worn down. It may well be that tooth eruption proceeds during adulthood simply because the forces causing eruption are never disabled.

The present study shows that lower face height is enhanced because the tooth itself migrates occlusally (presumably in both arcades; Iseri and Solow, 1996) but also because bone is proliferating apace with the teeth. The present study also documents the significantly greater rate of growth in men than women, notably in the vertical dimension. This is consistent with cephalometric studies of changes during adulthood (e.g., Forsberg, 1979; Behrents, 1986; Bishara et al., 1994) where growth is notably greater in men. The same has been reported from earlier, cross-sectional craniometric studies of dentate adults (Lasker, 1953; Thompson and Kendrick, 1964). This also was documented by West and McNamara (1999) who suggested that the increase in lower face height "probably is compensatory, resulting from either continued dental eruption, continued alveolar growth, or both, to balance the occlusions with the skeletal growth that is occurring." Opinions may differ as to what skeletodental changes are "balancing" and compensatory and which are passive respondents, but the net effect is slow but cumulative increase in adult facial dimensions, and the present study confirms that both tooth eruption and alveolar growth are contributory.

\section{Root Length}

At first impression, it probably is surprising to find that root length increased with age in this study, both for M1 and M2 and in both sexes. Indeed, the more common issue in the orthodontic literature deals with how treatment causes apical root resorption (Samehsima and Sinclair 2001a,b; Harris 2000), though there seems to be no posttreatment progression of the problem (Remington et al., 1989). Review of the literature suggests that there are very few longitudinal studies of root dimensions in adults. Cross-sectional studies, such as by Woods and coworkers (1990), typically encounter too much inter-individual variability to find any trend with age. The study by Bishara et al. (1999) is the most informative here. Bishara and coworkers had periapical films of the same 26 individuals at an average age of about 25 years and again at 45 years of age. Six of their comparisons of 32 root lengths (of 28 teeth) exhibited statistically significant increases in root length over time. However, when the Bonferroni correction for multiple comparisons was applied (which may be too conservative-see Holm, 1979; Rice, 1989), none of the changes remained significant. This led the authors to conclude "that there were no significant changes in root lengths between 25 and 45 years of age in either males or females."

This conclusion is perhaps overly cautious since other 
studies-albeit cross-sectional-have found that root lengths increase discernibly with age. Researchers have consistentlyattributed theseincreases totheaccumulation of cementum, which is known to accumulate at a fairly regular pace (Wittwer-Backofen et al. 2004). Levers and Darling (1983) reported "continuous lengthening" of the roots with age, "presumably by cementum deposition." Whittaker et al. (1990) found that root apices migrated away from the IAC significantly less than the CEJ, which they attributed to cementum apposition that lengthened the roots. Similarly, Varrela et al. (1990) reported that the CEJ-AP distances increased across age grades, with the most notable increases on M2.

\section{SUMMARY}

This longitudinal study spans late adolescence and early adulthood ( $c a .17$ to 30 years of age). Continued occlusal eruption is documented for the mandibular molars, with significantly greater changes in men than women. Importantly, the alveolar bone proliferated at the same rate, so crestal bone height remains the same distance from the molar's CEJ. Continuous eruptionin the effective absence of attrition-contributes to increasing lower face height.

\section{LITERATURE CITED}

Begg RP. 1954. Stone age man's dentition: with reference to anatomically correct occlusion, the etiology of malocclusion, and a technique for its treatment. Am J Orthod 40:298-312, 373-383, 462-475, 517-531.

Begg RP, Kesling PC. 1971. Begg orthodontic theory and technique, 2nd ed. Philadelphia: WB Saunders.

Behrents RG. 1985. Growth in the aging craniofacial skeleton. Monograph 17, Craniofacial Growth Series. Ann Arbor: Center for Human Growth and Development, University of Michigan.

Bhaskar SN. 1962. Synopsis of oral histology. St Louis: CV Mosby Company.

Bishara SE, Treder JE, Jakobsen JR. 1994. Facial and dental changes in adulthood. Am J Orthod Dentofac Orthop 106:175-186.

Bishara SE, Vonwald L, Jakobsen JR. 1999. Changes in root length from early to mid-adulthood: resorption or apposition? Am J Orthod Dentofacial Orthop 115:563-568.

Björk A. 1956. Facial growth in man, studied with the aid of metallic implants. Acta Odont Scand 13:9-34.

Björk A. 1963. Variations in the growth pattern of the human mandible: longitudinal radiographic study of the implant method. J Dent Res 42:400-411.

Björk A. 1968. The use of metallic implants in the study of facial growth in children: method and application. Am J Phys Anthropol 29:243-254.

Björk A, Skieller V. 1972. Facial development and tooth eruption. Am J Orthod 62:339-383.

Björk A, Skieller V. 1977. Growth of the maxilla in three dimensions as revealed radiographically by the implant method. Br J Orthod 4:53-64.

Bland JM, Altman DG. 1996. Measurement error. BMJ 313:744.

Carranza FA, Newman MG. 1996. Glickman's clinical periodontology, 7th ed. Philadelphia: WB Saunders.

Cevidanes LH, Bailey LJ, Tucker SF, Styner MA, Mol A, Phillips CL, Proffit WR, Turvey T. 2007. Threedimensional cone-beam computed tomography for assessment of mandibular changes after orthognathic surgery. Am J Orthod Dentofacial Orthop 131:44-50.

Cevidanes LH, Styner MA, Proffit WR. 2006. Image analysis and superimposition of 3-dimensional cone-beam computed tomography models. Am J Orthod Dentofacial Orthop 129:611-618.

Compagnon D, Woda A. 1991. Supraeruption of the unopposed maxillary first molar. J Prosthet Dent 66:29-34.

Dahlberg G. 1940. Statistical methods for medical and biological students. London: George Allen and Unwin, Ltd.

Dannenberg PJ, Hirsch RS, Clarke NG, Leppard PI, Richards LC. 1991. Continuous tooth eruption in Australian aboriginal skulls. Am J Phys Anthropol 85:305-312.

Durham TM, Goddard T, Morrison S. 2004. Rapid forced eruption: a case report and review of forced eruption techniques. Gen Dent 52:167-175.

Enlow DH. 1977. The remodeling of bone. Yrbk Phys Anthropol 20:19-34.

Enlow DH, Harris DB. 1964. A study of the postnatal growth of the human mandible. Am J Orthod 50:2550.

Forsberg CM. 1979. Facial morphology and ageing: a longitudinal cephalometric investigation of young adults. Eur J Orthod 15-23.

Gorski JP, Marks SC Jr. 1992. Current concepts of the biology of tooth eruption. Crit Rev Oral Biol Med 3:185-206.

Graber TM. 1967. Panoramic radiography in orthodontic diagnosis. Am J Orthod 53:799-821.

Harris EF. 2000. External apical root resorption resulting from orthodontic tooth movement. Semin Orthod 6:183-194.

Holm S. 1979. A simple sequentially rejective multiple test procedure. Scand J Statist 6:65-70.

Hurme VO. 1949. Ranges of normalcy in the eruption of permanent teeth. ASDC J Dent Child 16:11-15.

Iseri H, Solow B. 1996. Continued eruption of maxillary incisors and first molars in girls from 9 to 25 years, studies by the implant method. Eur J Orthod 18:245256.

Israel H. 1979. Evidence for continued apposition of adult mandibular bone from skeletalized materials. J Prosthet Dent 41:101-104.

Lasker GW. 1953. The age factor in bodily measurements 
of adult male and female Mexicans. Hum Biol 25:5063.

Lee CF, Proffit WR. 1995. The daily rhythm of tooth eruption. Am J Orthod Dentofac Orthop 107:38-47.

Levers BGH, Darling AI. 1983. Continuous eruption of some adult human teeth of ancient populations. Arch Oral Biol 28:401-408.

Manson JD. 1963. Passive eruption. Dent Practit 14:2-9.

Marks SC, Cahill DR. 1984. Experimental study in the dog of the nonactive role of the tooth in the eruptive process. Arch Oral Biol 29:311-322.

Moorrees CFA. 1957. The Aleut dentition: a correlative study of dental characteristics in an Eskimoid people. Cambridge: Harvard University Press.

Murphy T. 1959. Compensatory mechanisms in facial height adjustment to functional tooth attrition. Aust Dent J 4:312-23.

Newman HN, Levers BG. 1972. Tooth eruption and function in an early Anglo-Saxon population. J R Soc Med 72:341-350.

Ödman J, Gröndahl K, Lekhom U, Thilander B. 1991. The effect of osseointegrated implants on the dentoalveolar development: a clinical and radiographic study in growing pigs. Eur J Orthod 13:279-286.

Remington DN, Joondeph DR, Artun J, Riedel RA, Chapko MK. 1989. Long-term evaluation of root resorption occurring during orthodontic treatment. Am J Orthod Dentofacial Orthop 96:43-46.

Rice WR. 1989. Analyzing tables of statistical tests. Evolution 43:223-225.

Roberts WE. 1994. The use of dental implants in orthodontic therapy. In Davidovitch $\mathrm{A}$, ed. The biological mechanisms of tooth eruption, resorption and replacement by implants. Boston: Harvard Society for the Advancement of Orthodontics, p 631642.

Sameshima GT, Sinclair PM. 2001. Predicting and preventing root resorption: Part I. diagnostic factors. Am J Orthod Dentofacial Orthop 119:505-510.

Sameshima GT, Sinclair PM. 2001. Predicting and preventing root resorption: Part II. treatment factors. Am J Orthod Dentofacial Orthop 119:511-515.

Sato S, Parsons P. 1990. Eruption of permanent teeth: a color atlas. St Louis: Ishiyaku EuroAmerica, Inc.

Sokal RR, Rohlf FJ. 1995. Biometry: the principles and practice of statistics in biological research, 3rd ed. San Francisco: WH Freeman and Company.

Steedle JR, Proffit WR. 1985. The pattern and control of eruptive tooth movements. Am J Orthod 87:56-66.

Stevens BH, Levine RA. 1998. Forced eruption: a multidisciplinary approach for form, function, and biologic predictability. Compend Contin Educ Dent 19:994-998, 1000, 1002-1004.

Thompson JL, Kendrick GS. 1964. Changes in the vertical dimensions of the human male skull during the third and fourth decades of life. Anat Rec 150:209-214.

Trentini CJ, Brown WH, Paterson RL, Proffit WR. 1995. The application of Moire magnification to highresolution studies of human premolar eruption. Arch Oral Biol 40:623-629.

Varrela TM, Paunio K, Wouters FR, Tiekso J, Soder PO. 1995. The relation between tooth eruption and alveolar crest height in a human skeletal sample. Arch Oral Biol 40:175-180.

West KS, McNamara JA Jr. 1999. Changes in the craniofacial complex from adolescence to midadulthood: a cephalometric study. Am J Orthod Dentofacial Orthop 115:521-532.

Whittaker DK. 1985. The effect of continuing eruption on bone growth at the alveolar margin. Prog Clin Biol Res 187:259-267.

Whittaker DK, Griffiths S, Robson A, Roger-Davies P, Thomas G, Molleson T. 1990. Continuing tooth eruption and alveolar crest height in an eighteenthcentury population from Spitalfields, east London. Arch Oral Biol 35:81-85.

Whittaker DK, Parker JH, Jenkins C. 1982. Tooth attrition and continuing eruption in a Romano-British population. Arch Oral Biol 27:405-409.

Winer BJ, Brown DR, Michels KM. 1991. Statistical principles in experimental design, 3rd ed. New York: McGraw-Hill Book Company.

Wise GE, Frazier-Bowers S, D'Souza RN. 2002. Cellular, molecular, and genetic determinants of tooth eruption. Crit Rev Oral Biol Med 13:323-334.

Wittwer-Backofen U, Gampe J, Vaupel JW. 2004. Tooth cementum annulation for age estimation: results from a large known-age validation study. Am J Phys Anthropol 123:119-129.

Woods MA, Robinson QC, Harris EF. 1990. Ageprogressive changes in pulp widths and root lengths during adulthood: a study of American blacks and whites. Gerodontology 9:41-50.

Yonezu T, Machida Y. 1997. Occlusal migration of the maxillary first primary molars subsequent to the loss of antagonists. Bull Tokyo Dent Coll 38:201-206. 